\title{
The effect of the preceding day's protein intake on basal metabolic rates in young adults
}

\author{
BY M. J.SOARES, JENNIFER SEQUEIRA AND P. S. SHETTY* \\ Nutrition Research Centre (ICMR), Department of Physiology, St John's Medical \\ College, Bangalore 560034, India
}

(Received 7 June 1988 - Accepted 12 July 1988)

1. Changes in basal metabolic rates (BMR), following alterations in the preceding day's dietary protein $(8 \cdot 6$, 11.5 and $14.0 \%$ of energy) were studied in eight, young, healthy adults over $4 \mathrm{~d}$.

2. Results showed a significant training effect, with BMR values $4.8 \%$ lower on day 4 of the study period. Analysis of the results by ANOVA revealed a significant interaction between subjects and diets $(P<0.005)$, a significant difference between subjects but no differences in BMR due to the protein content of the diets.

3. Mean coefficient of variation (CV) for intra- and inter-individual differences in BMR from day-to-day was of the order of 4 and $9 \%$ respectively.

4. Changes in protein content of the preceding day's diet do not influence variations in BMR which appear to be random in nature with a true CV of $3.8 \%$.

An experimental demonstration that variations in dietary intake on a day-to-day basis may be followed by changes in energy expenditure has important consequences. If variations in the preceding day's diet are going to affect basal metabolic rate (BMR) measurements made 12-14 $\mathrm{h}$ later, then the methodology of such a measurement has to be re-examined in view of the general assumption that $12-14 \mathrm{~h}$ is sufficient time to exclude the effect of diet, such that the subjects are truly in a basal state. Recent reports affirming the wide variability in daily energy intakes (de Boer et al. 1987; Rao, 1987) indicate that a substantial portion of the total variation (about $70 \%$ ) is largely the result of within-subject or intra-individual variations in energy intake. This has lead to the unsubstantiated claim that the intraindividual variations in energy expenditure are also large, even in subjects accustomed to similar activities, and that these variations need to be considered while assessing the energy requirements of an individual (Sukhatme \& Narain, 1983). If this is true then the BMR, which constitutes the largest component (approximately 65\%) of the energy expenditure of an individual, should show concomitant changes with variations in dietary intake.

Studies on the effect of the preceding day's energy intake on expenditure have yielded conflicting results. While Miller \& Wise (1975), Garby \& Lammert (1977) and Stock (1980) have shown no changes in energy expenditure at rest or during light exercise consequent to alterations in the energy intake, studies by Dauncey (1980) have shown a substantial increase of $12 \%$ in the BMR of subjects who were overfed by about $5 \mathrm{MJ}$ the previous day. A recent study of Lammert et al. (1987), where subjects were given 4, 10 and $16 \mathrm{MJ}$, a change similar to that used by Dauncey (1980), showed no changes in the energy cost of rest, as well as arm and leg exercise. As the nutrient compositions of the meals were similar for all days in the previously mentioned study, we wondered whether changes in protein content could induce changes in BMR, since it has been reported that low protein intakes can depress the BMR (Mitchell, 1964). In the present study, we aimed at critically examining the changes in BMR of young adult males, whose preceding day's dietary intake provided a constant amount of energy but differed in the protein content. 


\section{METHODS}

Eight, healthy, young, adult males (age 19-24 years, body-weight $50 \cdot 2-68 \cdot 0 \mathrm{~kg}$, height $1.68-1.83 \mathrm{~m}$ ) participated in the study. Since the subjects were free living, the nature of the experiment was explained to them to ensure that all food was eaten only in the laboratory, though knowledge about the composition and order of diet was withheld. They were also requested to avoid any strenuous form of exercise on the evenings of the experimental days, since it could affect the next morning's BMR recording (Bielinski et al. 1985).

\section{Experimental diets}

The subjects were provided with meals for three consecutive days, with each day's diet being isoenergetic but differing in its protein content. The three diets (diets $\mathrm{A}, \mathrm{B}$ and $\mathrm{C}$ ) had an energy value of $10.04 \mathrm{MJ}$ and a protein content of $0.9,1.2$ and $1.5 \mathrm{~g} / \mathrm{kg}$ body-weight respectively. Each subject received the diets in a random order, with lunch and dinner each contributing one-third of the day's energy, while breakfast and two coffee breaks made up the total. The diets were in part composed of standardized commercially available foods, while all cooked meals were purchased from the hospital cafeteria where they were freshly prepared. All meals were consumed in the laboratory where their energy content and composition were determined by weighing and using standard tables for Indian food (Swaminathan et al. 1981 ; Pasricha \& Rebello, 1982; Gopalan et al. 1985). Care was taken to prescribe diets that were constant in their energy value and percentage fat, while variations in protein were reciprocal to those of carbohydrate. The gross composition of the diets for the $3 \mathrm{~d}$ is shown in Table 1 .

\section{$B M R$}

After an overnight stay in the laboratory, BMR was measured under standard conditions on four consecutive mornings ( $\mathrm{ad}$ lib. diet or diets A, B and C) between 06.30 and 08.30 hours in a room where temperatures ranged from $25^{\circ}$ to $28^{\circ}$, barometric pressure from 685.2 to $688 \mathrm{mmHg}$, and relative humidity from 63.9 to $87.5 \%$. BMR measurements were made for 10 min using a Hartmann and Braun Metabolator, which measured ventilation volumes, oxygen and carbon dioxide concentrations (as the difference from atmospheric air) from which the respiratory quotient (RQ) could be calculated. Duplicate measurements, 15 min apart, were considered technically valid, if they were within $\pm 3 \%$ of the mean of the two readings. In the present study, on average, the BMR values were within $\pm 1.6 \%$ of their means. The resting heart rate and blood pressure of each subject were monitored during the measurement period while the height, weight and skinfolds (biceps, triceps, subscapular and supra-iliac) were recorded after the BMR measurements on days 1 and 3 of the study period.

\section{Statistical analysis and ethical considerations}

The values were subjected to a paired $t$ test as well as a two-way analysis of variance (ANOVA) model II (Sokal \& Rohlf, 1969) to check for differences in BMR due to diets and differences between subjects. Differences were considered significant at a level of $P<0.05$. True intra-individual variation in BMR separated from measurement error was calculated using one-way model II ANOVA for each subject. Ethical approval was given by the Ethical Committee of the Institution and informed consent was obtained from each subject. 


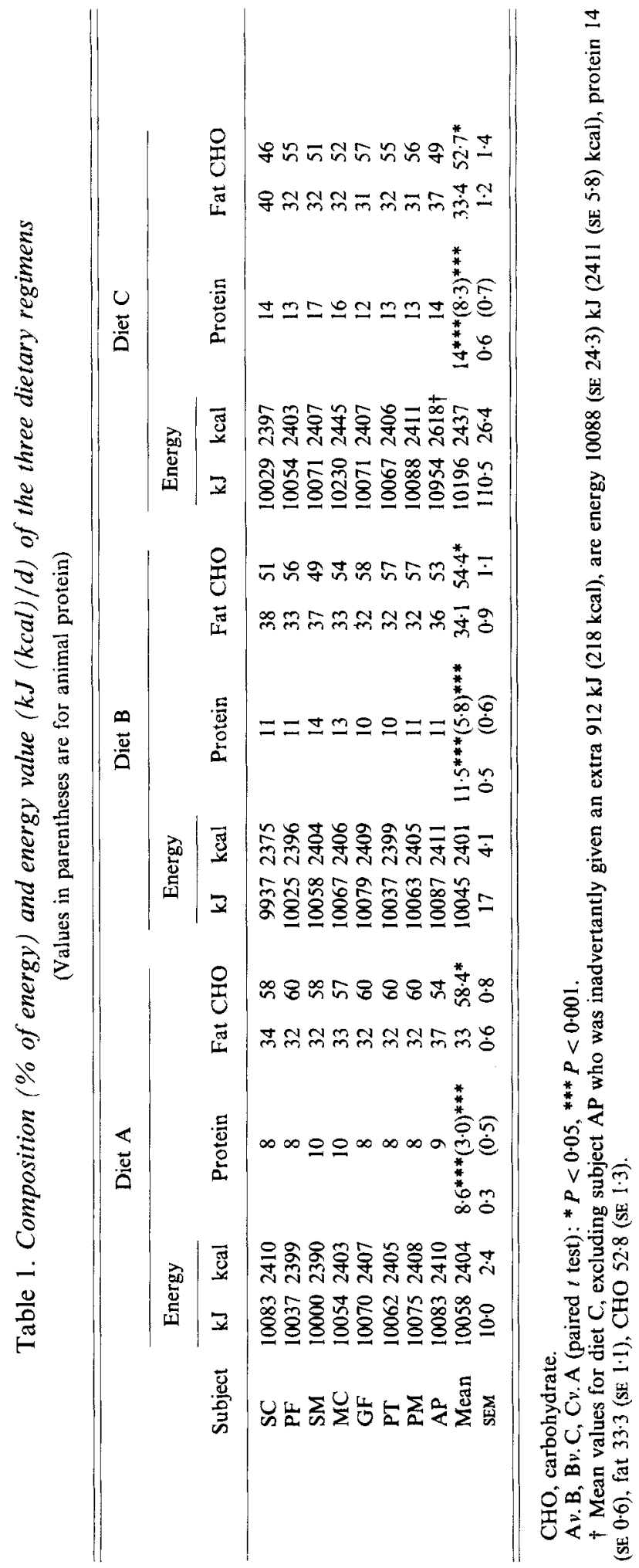




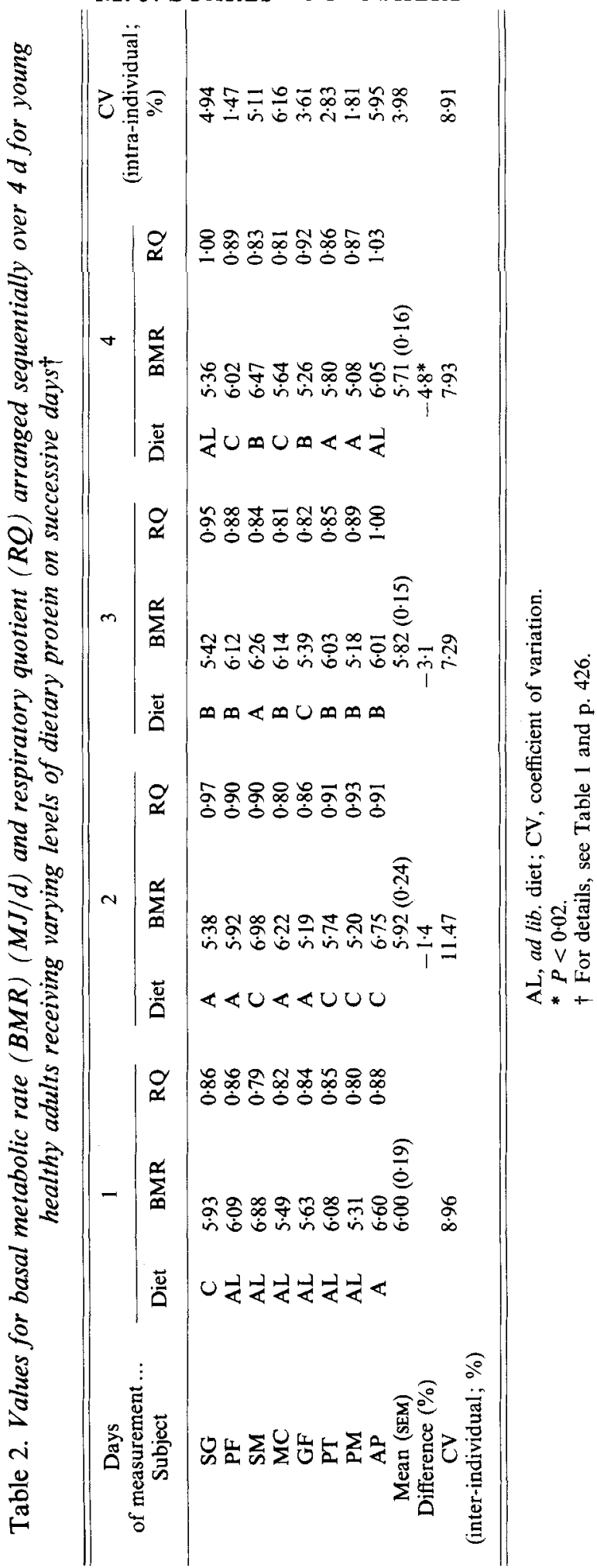


Table 3. Two-way analysis of variance (model II) of basal metabolic rate (BMR) values for young healthy adults receiving varying levels of dietary protein $\dagger$

\begin{tabular}{|c|c|c|c|c|c|}
\hline Source & $\mathrm{df}$ & Sum of squares & Mean square & $F$ ratio & $\begin{array}{c}\text { Statistical } \\
\text { significance: } \\
P\end{array}$ \\
\hline Between diets & 2 & 0.1911 & $0.09555^{*}$ & 0.5193 & NS \\
\hline Between subjects & 7 & $10 \cdot 9181$ & $1.5597^{*}$ & 8.4766 & $<0.005$ \\
\hline $\begin{array}{l}\text { Interaction } \\
\text { (subject v. diet) }\end{array}$ & 14 & $2 \cdot 5766$ & $0 \cdot 1840$ & 6.5504 & $<0.005$ \\
\hline Between replicates & 24 & 0.6742 & 0.02809 & - & - \\
\hline
\end{tabular}

NS, Not significant.

* Significance tested over interaction term.

$\dagger$ For details, see Table 1 and p. 426.

\section{RESULTS}

Experimental diets

The gross composition of the diets on the $3 \mathrm{~d}$ (Table 1) showed no significant differences in energy and percentage fat between the $3 \mathrm{~d}$ (paired $t$ test, not significant), while protein and carbohydrate intakes were significantly different and varied reciprocally from diets $\mathrm{A}$ to $\mathrm{B}$ to $\mathrm{C}$. The increase in protein was mainly due to a significant increase in the animal protein, while the vegetable fraction remained constant.

\section{$B M R$}

The results are summarized in Tables 2 and 3. Irrespective of the preceding day's dietary intake, an analysis of the BMR values showed a distinct training effect (Table 2) with a decline in BMR values from day 1 to day $4(P<0.02)$. A paired $t$ test between BMR values following the different dietary regimens showed no significant effect due to the diets. An ANOVA of the same values (Table 3 ) showed the presence of a significant interaction between subjects and diets $(P<0.005)$, a significant difference between subjects $(P<0.005)$, but no differences between the diets. True intra-individual variation in BMR had a CV of $3.8 \%$ while the CV of measurement error was $2.4 \%$. There were no statistically significant changes in body-weight over the $4 \mathrm{~d}$ of the study (paired $t$ test, not significant) with a mean $\mathrm{CV}$ of body-weight change of only $0.4 \%$.

\section{DISCUSSION}

The concensus of an Expert Consultation of the Food and Agriculture Organization/ World Health Organization/United Nations University (FAO/WHO/UNU) to assess the energy requirements of individuals or population groups from measurements of energy expenditure rather than energy intake (FAO/WHO/UNU, 1973) and the subsequent decision to predict energy expenditure from BMR measurements using the factorial method (FAO/WHO/UNU, 1985) increases the importance of studies on BMR, its methodology and biological variation. That changes in the preceding day's diet can affect a subsequent BMR measurement (Dauncey, 1980), together with the claim that variations in energy expenditure of the same individual are large (Sukhatme \& Narain, 1983), necessitates investigations in these areas, as the results have serious implications while assessing energy requirements of individuals or population groups by the FAO/WHO/ UNU (1985) method. 
In the present study we have manipulated the diets of a group of individuals such that each diet was isoenergetic but had varying levels of protein. The BMR measured following such meals given in a random order (Table 2) showed a decline from day-to-day with values by day 4 being $4.8 \%$ lower $(P<0.02)$ than the initial value. This training or familiarization effect is similar to, but of a lesser magnitude than that seen for subjects measured from week-to-week over 6 weeks (Soares \& Shetty, 1986) and indicates that much of the variations seen in BMR from day-to-day may probably be due to methodology, since biological variations are more likely to be random about a mean value. Analysis by a paired $t$ test of BMR values following the three diet days showed no significant differences and this was also true for a comparison between the BMR of the ad lib.-diet day and diets A, B and C respectively. Analysis by two-way ANOVA model II (Sokal \& Rohlf, 1969) detected the presence of a significant interaction between subjects and diets (Table 3 ). This would mean that the level of expression of the measured variable $\left(\mathrm{O}_{2}\right.$ consumption $)$ was affected by the combination of each subject and each diet, but the data as a whole showed no trend, leading to an insignificant difference in the treatment effect (between diets $P>0.05$ ). There was, however, a significant difference between subjects $(P<0.005)$, with a $\mathrm{CV}$ of BMR changes over the $4 \mathrm{~d}$ of the order of $9 \%$ (Table 2). The mean CV of intra-individual variations over the same period was only $4 \%$. Hence changes in the preceding day's protein intake made no difference to the BMR measured the following day and therefore the criteria currently adopted for a BMR measurement hold.

An analysis of the true intra-individual variations in BMR separated from measurement error using a one-way model II ANOVA (Sokal \& Rohlf, 1969) for each subject, gives the following results:

$\begin{array}{ccccc} & \text { Body-weight } & \text { BMR } & \text { RQ } & \text { Measurement error } \\ \text { CV }(\%) & 0.4 & 3.8 & 4 \cdot 3 & 2 \cdot 4\end{array}$

This small CV of intra-individual differences in BMR on a day-to-day basis was similar to the CV of intra-individual differences (CV 2.9\%) when free-living subjects were measured from week-to-week (Soares \& Shetty, 1986) and similar to the CV of intra-individual differences (CV 3.2\%) in BMR measured over varying time-intervals (6-36 months) in subjects who had maintained body-weight over this period (Soares \& Shetty, 1987). Results from other studies over the last 50 years also show comparable values with the $\mathrm{CV}$ of within-subject variations in BMR being at no time greater than $5 \%$ (Shetty \& Soares, 1988). The results of the present study and the overwhelming past evidence tends to support the view that intra-individual variations in BMR are small and probably insignificant, even when energy or protein intakes or activity patterns of the individual are not controlled. We therefore share the opinion of Mitchell (1964) that the BMR of human adults is relatively constant and the range of variations seen within subjects are no greater than that for other physiological values.

The experimental demonstration that variations in daily energy intake are followed by equivalent changes in energy expenditure would help explain the mechanisms underlying the process of energy balance as well as explain a considerable part of the within- and between-subject variation in energy expenditure. The results of Dauncey (1980) are important in this regard, where an increase in energy intake by about $5 \mathrm{MJ}$ produced an increase of about $12 \%$ in BMR the following morning. However, this is in contrast to the studies of Miller \& Wise (1975), Garby \& Lammert (1977), Stock (1980) and Lammert et al. (1987) who showed an insignificant change in energy expenditure during rest and light activity following changes in the preceding day's energy intake. In the light of this evidence, together with the results of the present study, one could conclude that variations in the preceding day's energy intake or in the protein content of the diet are not accompanied by significant changes in an individual's energy expenditure at rest, which are, instead, random 
in nature when measured from day-to-day, with a CV within the same individual always less than $5 \%$.

This study was supported by the Indian Council of Medical Research.

\section{REFEREN CES}

Bielinski, R., Schutz, Y. \& Jequier, E. (1985). American Journal of Clinical Nutrition 42, 69-82.

Dauncey, M. J. (1980). British Journal of Nutrition 43, 257-269.

de Boer, J. O., Knuiman, J. T., West, C. E., Burema, J., Rasanen, L., Scaccini, C., Villavieja, G. M. \& Lokko, P. (1987). Human Nutrition: Applied Nutrition 41A, 225-232.

Food and Agriculture Organization/World Health Organization/United Nations University. (1973). Energy and Protein Requirements. WHO Technical Reports Series, no. 522. Geneva. WHO.

Food and Agriculture Organization/World Health Organization/United Nations University. (1985). Energy and Protein Requirements. WHO Technical Report Series, no. 724. Geneva: WHO.

Garby, L. \& Lammert, O. (1977). Acta Physiologica Scandinavica 101, 411-417.

Gopalan, C., Ramasastri, B. V. \& Balasubramanian, S. C. (1985). Nutritive Value of Indian Food. Hyderabad: National Institute of Nutrition, Indian Council of Medical Research.

Lammert, O., Garby, L., Maron, K., Mork, G., Myo, Thein., Flindt-Egeback, P. \& Krogh-Hansen, J. (1987). Human Nutrition: Clinical Nutrition 41C, 141-147.

Miller, D. S. \& Wise, A. (1975). Lancet i, 1290.

Mitchell, H. H. (1964). Comparative Nutrition of Man and Domestic Animals, vol. 1. London: Academic Press.

Pasricha, S. \& Rebello, L. M. (1982). Some Common Indian Recipes and Their Nutritive Value, 4th ed. Hyderabad: National Institute of Nutrition, Indian Council of Medical Research.

Rao, S. (1987). Human Nutrition: Clinical Nutrition 41C, 71-79.

Shetty, P. S. \& Soares, M. J (1988). In Comparative Nutrition [K. Blaxter and I. Macdonald, editors]. London: John Libbey (in the Press).

Soares, M. J. \& Shetty, P. S. (1986). Human Nutrition: Clinical Nutrition 40C, 365-369.

Soares, M. J. \& Shetty, P. S. (1987). Human Nutrition: Clinical Nutrition 41C, 287-290.

Sokal, R. R. \& Rohlf, F. J. (1969). Biometry: The Principles and Practise of Statistics in Biological Research. San Francisco: W. H. Freeman.

Stock, M. J. (1980). European Journal of Applied Physiology 43, $35-40$.

Sukhatme, P. V. \& Narain, P. (1983). Indian Journal of Medical Research 78, 857-865.

Swaminathan, M., Joseph, K., Narayana Rao, M., Chandriamani, S. V., Subramanyam, L. \& Indira, K. (1981). Balanced Diets and Nutritive Value of Common Recipes, 2nd ed. Mysore: Central Food Technological Research Institute, Council for Scientific and Industrial Research. 